\title{
Effect of insulin pump infusion on comprehensive stress state of patients with diabetic ketoacidosis
}

\author{
Wen-Jun Jiao, Hua Li*, Tian-Yi Li, Tao Feng, Su-Jun Li \\ Department of Geriatric Endocrinology, The First Affiliated Hospital of Zhengzhou University, Zhengzhou, Henan 450052, PR \\ China \\ *For correspondence: Email: hualijwj@163.com
}

\begin{abstract}
Purpose: To assess changes in the comprehensive stress state of patients with diabetic ketoacidosis (DKA) following treatment with insulin infusion pump.

Methods: A total of 240 patients suffering from DKA who received treatment at The First Affiliated Hospital of Zhengzhou University from Feb. 2011 to Feb. 2014 were selected randomly and divided into a control group (120 cases), administered continuous intravenous insulin, and a treatment group (120 cases), administered insulin with an infusion pump. Relevant diabetes-associated serum indices, oxidative stress and stress hormone levels were compared between the groups at different time points. Results: Levels of glycosylated haemoglobin (HbAlc), fasting blood glucose (FBG) and anion gap (AG) were lower $(p<0.05)$ in the treatment group than in the control group at various time points. Carbon dioxide combining power $\left(\mathrm{CO}_{2}-\mathrm{CP}\right)$ and $\mathrm{C}$-reactive peptide levels in the treatment group were higher ( $p$ $<0.05)$ than those of the control group at different time points. Except for the level of methane dicarboxylic aldehyde $(M D A)$, the values of other oxidative stress indices were higher $(p<0.05)$ in the treatment group than in the control group at various time points. Moreover, the treatment group had lower serum cortisol (Cor) and noradrenalin (NA) levels and higher levels of free triiodothyronine (FT3), free thyroxine (FT4) and thyroid-stimulating hormone (TSH) than those of $(p<0.05)$.

Conclusion: Insulin pump infusion effectively relieves the comprehensive stress state of patients suffering from DKA, and its therapeutic effect is superior to that of continuous instillation of low-dose insulin.
\end{abstract}

Keywords: Diabetic ketoacidosis, Insulin pump, Comprehensive stress state, Blood glucose, Carbon dioxide combining power, C-reactive peptide

Tropical Journal of Pharmaceutical Research is indexed by Science Citation Index (SciSearch), Scopus, International Pharmaceutical Abstract, Chemical Abstracts, Embase, Index Copernicus, EBSCO, African Index Medicus, JournalSeek, Journal Citation Reports/Science Edition, Directory of Open Access Journals (DOAJ), African Journal Online, Bioline International, Open-J-Gate and Pharmacy Abstracts

\section{INTRODUCTION}

Diabetic ketoacidosis (DKA) refers to pathological changes, such as hyperglycaemia, hyperketonaemia, electrolyte disturbance, metabolic acidosis and ketonuria, as a result of insulin insufficiency under the effects of acute infection, improper treatment or metabolic disturbances induced by a diet failing to control diabetes [1,2]. Insulin insufficiency is the leading cause of DKA. Thus, the key to treating DKA is to correct the acidosis and hyperketonaemia induced by acute metabolic disturbance by providing low-dose insulin $[3,4]$.

The conventional therapy for DKA is continuous intravenous injection of low-dose insulin, but it is associated with complications, such as a slow recovery of blood glucose levels, a high risk of hypoglycaemia, and slow negative conversion of ketone bodies [5]. Insulin instilled intravenously at a concentration of $20 \%$ was found to be 
absorbed by the wall of the infusion tube; thus, the curative effect of insulin administered via this method is decreased by absorption [6]. Currently, an insulin pump is considered an effective treatment for DKA $[7,8]$. Such a system consists of a pump, small injector and infusion tube that continuously infuses insulin beneath the skin of patients to maintain a stable blood glucose level by simulating pancreatic secretion. Consequently, patients absorb insulin continuously, thereby maintaining a highly stable blood insulin concentration. Moreover, the primary dose prior to eating can be adjusted according to disease conditions and blood glucose levels. Using an insulin pump, blood glucose is maintained at a normal level, and glycosylated haemoglobin (HbAlc) and the incidence of hypoglycaemia are reduced significantly $[9,10]$.

In a DKA state, acute hyperglycaemia and fluctuations in blood glucose levels can result in the changes in oxidative stress and stress hormone levels [11]. This study explored the effects of insulin pump treatment on the comprehensive state of patients suffering from DKA.

\section{METHODS}

\section{Subjects}

A total of 240 patients who were suffering from DKA who received treatment at the First Affiliated Hospital of Zhengzhou University, Zhengzhou, Henan, China between February 2011 and February 2014 were selected as research subjects. The study was approved by the Medical Ethics Committee of The First Affiliated Hospital of Zhengzhou University (approval number: JWJ20150627), and conformed to the principles of the Declaration of Helsinki [12]. Patients aged 35-65 years who met the diagnostic criteria for DKA and had a blood glucose level > 13.9 $\mathrm{mmol} / \mathrm{L}$, blood $\mathrm{pH}<7.35$, ketonuria positivity, anion gap $(A G)>16 \mathrm{mmol} / \mathrm{L}$ and $\mathrm{HCO}_{3}$ level < $18 \mathrm{mmol} / \mathrm{L}$ were included. Patients with DKA induced by acute cardiovascular and cerebrovascular diseases, gastrointestinal haemorrhage, major surgery or pregnancy were excluded. Patients $(\mathrm{N}=240)$ were divided randomly into treatment and control groups using a random number table.

\section{Methods}

Patients in the two groups were administered supportive treatment, such as fluid infusion, acidbase imbalance correction and electrolyte disturbance correction, upon admission to the hospital. Patients in the control group were treated with intravenous instillation of low-dose insulin (4-6 U/h), whereas patients in the treatment group were treated with intravenous insulin administered by an insulin pump at a rate of 4-6 U/h. The peripheral blood glucose level was measured before eating, $2 \mathrm{~h}$ after eating, and before bedtime. The dose of insulin was adjusted according to disease condition.

\section{Observation indices}

Blood gas analysis, measuring carbon dioxide combining power $\left(\mathrm{CO}_{2}-\mathrm{CP}\right)$ and $A G$ levels, was performed in all patients at admission and $2 \mathrm{~h}$ and $24 \mathrm{~h}$ after treatment. Elbow venous blood (5 $\mathrm{mL}$ ) was drawn from each patient at different time points. The blood samples were centrifuged, and the supernatant was used for determination of levels of HbAlc, fasting blood glucose (FBG)) and C-reactive peptide and oxidative stressassociated indices, including superoxide dismutase (SOD), malondialdehyde (MDA), glutathione peroxidase (GSH-PX) and the total antioxidant capacity (TAC), as well as levels of stress-associated hormones, including cortisol (Cor), noradrenalin (NA), free triiodothyronine (FT3), free thyroxine (FT4) and thyroidstimulating hormone (TSH).

The FBG level was measured using a fully automatic biochemical analyser. The HbAlc level was measured using high-performance liquid chromatography. Levels of C-reactive peptide, Cor, SOD, MDA, GSH-PX and TAC were measured using chemiluminescence methods. Levels of the other hormones were measured using enzyme linked immunosorbent assay (ELISA).

\section{Statistical analysis}

Data were analysed using SPSS software (ver. 19.0) and expressed as mean \pm SD. Comparisons between groups were performed using independent-sample t-tests. Enumerated data were compared using $x^{2}$ tests. Differences were considered statistically significant when $p<$ 0.05 .

\section{RESULTS}

\section{General data}

The control group consisted of 64 males and 56 females, with an average age of $52.63 \pm 7.21$ years, body mass index (BMI) of $23.92 \pm 2.03$ $\mathrm{kg} / \mathrm{m}^{2}$ and duration of diabetes of $7.65 \pm 2.13$ years. There were 62 cases of hypertension and 34 of coronary heart disease. The treatment 
group consisted of 66 males and 54 females, with an average age of $53.14 \pm 7.28$ years, BMI of $24.03 \pm 2.12 \mathrm{~kg} / \mathrm{m}^{2}$ and duration of diabetes of $7.87 \pm 2.08$ years. There were 66 cases of hypertension and 36 of coronary heart disease. Differences in sex, age, BMI and duration of diabetes between the two groups were not statistically significant; thus, the results were comparable.

\section{Diabetic indices before and after treatment}

No significant differences were observed in any of the indices between the two groups $(p>0.05)$. Levels of HbAlc, FBG and AG were much lower, and the $\mathrm{CO}_{2}-\mathrm{CP}$ and $\mathrm{C}$-reactive peptide levels higher, in the treatment group than the control group $2 \mathrm{~h}$ and $24 \mathrm{~h}$ after treatment (Table 1).

\section{Serum oxidative stress-associated indices}

Levels of SOD, GSH-PX and TAC showed no significant differences between the two groups before treatment ( $p>0.05)$. At $2 \mathrm{~h}$ and $24 \mathrm{~h}$ after treatment, the serum MDA level was much lower, and SOD, GSH-PX and TAC levels much higher, in the treatment group than the control group $(p<$ 0.05; Table 2).

\section{Stress hormone levels before and after treatment}

Differences in levels of serum Cor, NA, FT3, FT4 and TSH between the two groups were not statistically significant before treatment $(p>$ 0.05). Levels of serum Cor and NA were much lower, whereas the levels of FT3, FT4 and TSH were much higher, in the treatment group than the control group $(p<0.05) 2 \mathrm{~h}$ and $24 \mathrm{~h}$ after treatment (Table 3$)$.

\section{DISCUSSION}

DKA is a complication commonly observed in patients suffering from diabetes. Epidemiological investigations suggest that the incidence of DKA is between 15 and $45 \%$. DKA occurs when severe insulin insufficiency significantly weakens biological functions,

Table 1: Diabetic indices before and after treatment (mean \pm SD)

\begin{tabular}{|c|c|c|c|}
\hline Parameter & Time & Control group & Treatment group \\
\hline \multirow{3}{*}{ HbAlc (\%) } & $0 \mathrm{~h}$ & $14.03 \pm 3.92$ & $13.86 \pm 3.74$ \\
\hline & $2 \mathrm{~h}$ & $12.26 \pm 3.62$ & $9.01 \pm 3.66^{\pi}$ \\
\hline & $24 \mathrm{~h}$ & $7.11 \pm 2.06$ & $5.22 \pm 1.16^{\pi}$ \\
\hline \multirow{3}{*}{$\mathrm{CO}_{2}-\mathrm{CP}(\mathrm{mM})$} & $\mathrm{Oh}$ & $6.76 \pm 3.51$ & $6.78 \pm 3.47$ \\
\hline & $2 \mathrm{~h}$ & $8.92 \pm 3.68$ & $12.02 \pm 3.61^{\circ}$ \\
\hline & $24 \mathrm{~h}$ & $18.31 \pm 3.06$ & $0.47 \pm 0.17$ \\
\hline \multirow{3}{*}{ FBG (mM) } & $\mathrm{Oh}$ & $18.7 \pm 8.13$ & $18.90 \pm 8.02$ \\
\hline & $2 \mathrm{~h}$ & $17.08 \pm 6.72$ & $16.33 \pm 4.27^{\pi}$ \\
\hline & $24 \mathrm{~h}$ & $7.67 \pm 3.53$ & $6.85 \pm 2.01^{\pi}$ \\
\hline \multirow{3}{*}{$\mathrm{AG}(\mathrm{mM})$} & $\mathrm{Oh}$ & $33.46 \pm 8.37$ & $33.10 \pm 8.13$ \\
\hline & $2 \mathrm{~h}$ & $27.66 \pm 8.11$ & $24.04 \pm 8.46$ \\
\hline & $24 \mathrm{~h}$ & $21.62 \pm 7.04$ & $17.66 \pm 6.03^{\star}$ \\
\hline \multirow{3}{*}{$\begin{array}{l}\text { C-reactive peptide } \\
(\mathrm{ng} / \mathrm{mL})\end{array}$} & $\mathrm{Oh}$ & $0.05 \pm 0.03$ & $0.05 \pm 0.04$ \\
\hline & $2 \mathrm{~h}$ & $0.23 \pm 0.13$ & $21.37 \pm 3.16$ \\
\hline & $24 \mathrm{~h}$ & $0.73 \pm 0.26$ & $1.14 \pm 0.43$ \\
\hline
\end{tabular}

Note: * Significant difference $(p<0.05)$ versus control group

Table 2: Serum oxidative stress-associated indices before and after treatment (mean \pm SD)

\begin{tabular}{lccc}
\hline Parameter & Time & Control group & Treatment group \\
\hline \multirow{2}{*}{ SOD $(\mathrm{U} / \mathrm{L})$} & $0 \mathrm{~h}$ & $22.61 \pm 7.63$ & $22.96 \pm 7.70$ \\
& $2 \mathrm{~h}$ & $24.73 \pm 7.61$ & $26.61 \pm 7.45^{\star}$ \\
MDA $(\mathrm{nmol} / \mathrm{mL})$ & $24 \mathrm{~h}$ & $27.14 \pm 7.32$ & $31.32 \pm 8.01^{\star}$ \\
& $0 \mathrm{~h}$ & $8.97 \pm 2.11$ & $8.83 \pm 2.48$ \\
& $2 \mathrm{~h}$ & $8.97 \pm 2.12$ & $6.87 \pm 1.86^{\star}$ \\
$\mathrm{GSH}-\mathrm{PX}(\mathrm{U} / \mathrm{mL})$ & $24 \mathrm{~h}$ & $7.85 \pm 2.15$ & $4.06 \pm 1.92^{\star}$ \\
& $0 \mathrm{~h}$ & $73.64 \pm 9.67$ & $73.04 \pm 8.04$ \\
& $2 \mathrm{~h}$ & $75.65 \pm 9.33$ & $82.35 \pm 8.25^{\star}$ \\
TAC $(\mathrm{U} / \mathrm{mL})$ & $24 \mathrm{~h}$ & $86.05 \pm 9.16$ & $95.43 \pm 9.04^{\star}$ \\
& $0 \mathrm{~h}$ & $17.56 \pm 5.18$ & $17.87 \pm 5.17$ \\
& $2 \mathrm{~h}$ & $21.72 \pm 5.11$ & $24.23 \pm 6.04^{\star}$ \\
\hline
\end{tabular}

* Significant difference $(p<0.05)$ versus the control group. 
Table 3: Stress hormones before and after treatment (mean \pm SD)

\begin{tabular}{|c|c|c|c|}
\hline Parameter & Time & Control group & Treatment group \\
\hline & $0 \mathrm{~h}$ & $865.46 \pm 312.58$ & $851.71 \pm 306.66$ \\
\hline \multirow[t]{3}{*}{ Cor (nmol/L) } & $2 \mathrm{~h}$ & $813.62 \pm 261.38$ & $721.45 \pm 264.70^{x}$ \\
\hline & $24 \mathrm{~h}$ & $602.01 \pm 192.46$ & $478.32 \pm 131.61^{*}$ \\
\hline & $0 \mathrm{~h}$ & $817.96 \pm 413.65$ & $823.18 \pm 386.32$ \\
\hline \multirow[t]{3}{*}{ NA (ng/L) } & $2 \mathrm{~h}$ & $754.73 \pm 362.52$ & $674.62 \pm 231.62$ \\
\hline & $24 \mathrm{~h}$ & $531.67 \pm 205.16$ & $403.19 \pm 131.47^{\circ}$ \\
\hline & $\mathrm{Oh}$ & $2.85 \pm 1.22$ & $2.81 \pm 1.37$ \\
\hline \multirow[t]{3}{*}{ FT3 (pmol/L) } & $2 \mathrm{~h}$ & $2.97 \pm 1.26$ & $3.25 \pm 1.43^{\prime}$ \\
\hline & $24 \mathrm{~h}$ & $3.98 \pm 1.02$ & $4.20 \pm 1.38^{x}$ \\
\hline & $\mathrm{Oh}$ & $11.61 \pm 3.53$ & $11.67 \pm 3.30$ \\
\hline \multirow[t]{3}{*}{ FT4 (pmol/L) } & $2 \mathrm{~h}$ & $12.52 \pm 3.61$ & $13.48 \pm 3.16^{\circ}$ \\
\hline & $24 \mathrm{~h}$ & $14.23 \pm 3.01$ & $15.32 \pm 3.11^{\circ}$ \\
\hline & $\mathrm{Oh}$ & $1.80 \pm 0.76$ & $1.87 \pm 0.78$ \\
\hline \multirow[t]{2}{*}{ TSH (mIU/L) } & $2 \mathrm{~h}$ & $1.93 \pm 0.73$ & $2.01 \pm 0.76^{\pi}$ \\
\hline & $24 \mathrm{~h}$ & $2.33 \pm 0.87$ & $2.62 \pm 0.85^{\star}$ \\
\hline
\end{tabular}

* Significant difference $(p<0.05)$ versus the control group

such as cell differentiation and glucose utilisation, thereby increasing blood glucose levels. This resulting energy insufficiency accelerates cell differentiation and increases blood and urinary ketone levels, ultimately inducing the clinical symptoms and signs of metabolic acidosis [13,14]. Thus, the key to treating DKA is rapid control of the disease condition, and insulin treatment is absolutely necessary [15]. Low-dose insulin has great significance in the treatment of DKA. One study [16] suggested that early application of insulin effectively controlled acute onset of DKA by decreasing blood glucose levels, regulating the amplification cascade of inflammatory factors and relieving the stress state. Infusion of insulin using a insulin pump can help maintain stable blood insulin levels by controlling the infusion rate. Compared with conventional intravenous instillation of insulin, it can lower the level of blood glucose level more gradually and prevent hypoglycaemia [17].

In this study, the comprehensive stress state of patients with DKA was evaluated before and after micropump treatment, and the curative effect of the micropump was compared with that of intravenous instillation of low-dose insulin. The results demonstrated that the levels of $\mathrm{HbAlc}$, FBG, and AG were significantly lower, and the levels of $\mathrm{CO}_{2}-\mathrm{CP}$ and $\mathrm{C}$-reactive peptide much higher, in the treatment group than the control group, suggesting that insulin pump treatment induced a more rapid and stronger curative effect.

Patients with DKA demonstrate oxidative damage and high stress hormone levels. It has been found that the high expression of proinflammatory factors in patients with DKA can induce synthesis of acute-phase proteins, proliferation and differentiation of $\mathrm{T}$ cells, mass synthesis of reactive oxygen intermediates, leading to lipid peroxidation, and stress reactions [18]. Activation of the hypothalamus-pituitaryadrenal gland, gonads, thyroid gland axis, and sympathetic nervous system are also involved in the common stress reaction observed in DKA. Under DKA conditions, the body produces stress hormones such as epinephrine, noradrenalin and glucocorticoids to initiate stress defence mechanisms and induce systemic inflammatory reaction syndrome, which can ultimately lead to multiple organ failure [19-22]. In the present study, the improvements in oxidative stress and stress hormones observed in the treatment group were more obvious than those in the control group, suggesting that oxidative damage and stress were effectively controlled. Thus, the value and curative effect of an insulin micropump system in the treatment of DKA were confirmed.

\section{Limitations of the study}

Insulin pump treatment is not applicable to patients with severe DKA because of their poor insulin absorption which arises from circulatory failure. Thus, patients with severe DKA were not included in this study. The therapeutic effect of insulin pump in treating severe DKA needs further investigation.

\section{CONCLUSION}

Patients treated with insulin pump show more obvious changes in their comprehensive stress state, compared with those treated with intravenous instillation of low-dose insulin. Insulin pump treatment improves DKA-associated indices. Thus, insulin pump treatment, which can more effectively relieve the stress state and lower blood glucose levels of patients, needs 
further studies before it can be promoted for clinical application.

\section{DECLARATIONS}

\section{Acknowledgement}

The authors sincerely thank all who supported this work.

\section{Conflict of Interest}

No conflict of interest associated with this work.

\section{Contribution of Authors}

The authors declare that this work was done by the authors named in this article and all liabilities pertaining to claims relating to the content of this article will be borne by them.

\section{REFERENCES}

1. Xie L, Tayierjiang TEX. Comparison study of two different insulin delivery methods in the treatment of diabetic ketoacidosis. Jilin Med J 2013; 34(31): 6511-6512.

2. Wang Y. Clinical study of continuous subcutaneous insulin injection in the treatment of diabetic ketoacidosis. Acta Acad Med CPAPF 2010; 19(7): 538-540.

3. Wang X, Zhong JT, Jiang YZ, Ge XJ. Clinical observation of continuous subcutaneous insulin infusion in treatment of diabetic ketoacidosis. China J Mod Med 2008; 18(15): 2213-2215.

4. Kallas-Koeman MM, Kong JM, Klinke JA, Butalia S, Lodha AK, Lim KI, Duan QM, Donavan LE. Insulin pump use in pregnancy is associated with lower $H b A 1 c$ without increasing the rate of severe hypoglycaemia or diabetic ketoacidosis in women with type 1 diabetes. Diabet 2014; 57(4): 681-689.

5. Luo HJ. Curative effect of insulin in the treatment of diabetic ketoacidosis in 87 cases. Chin Community Doctors 2012; 14(12): 46.

6. Cui $\mathrm{XH}$, Sun YP. Application of insulin pump in the treatment of diabetic ketoacidosis. Contemp Med 2009, (28): 54.

7. Gu Z, Jiang XZ, Xu LY, Zhu ZH, Zhou B, Zou YF. Clinical study of insulin pump in the treatment of diabetic ketoacidosis. J Prac Diabet 2009; (6): 26.

8. Ding HC, Cheng CM, Liao YG. Clinical observation of insulin pump in the treatment of diabetic ketoacidosis. $J$ Clin Emerg Call 2009; 10(1): 33-35.
9. Zhang ZJ. The curative effect comparison between CAII and continuous intravenous insulin instilling treatment of DKA \& diabetic hyperosmolar syndrome. Chin J Diabet 2008; 16(7): 426-428.

10. Cheng EH, Zhu YZ, Peng HD, Zheng R, Zhang Z, Lu XX. Application of micropump insulin injection in the treatment of diabetic ketoacidosis. Chin J Clin Health 2012; 15(4): 344-346.

11. Ceriello A, Esposito K, Piconi L, Ihnat MA, Thorpe JE, Testa R, Boemi M, Giugliano D. Oscillating glucose is more deleterious to endothelial function and oxidative stress than mean glucose in normal and type 2 diabetic patients. Diabet 2008; 57(5): 1349-1354.

12. Declaration of Helsinki. The 59th World Medical Association, 2008.

13. Shan $C Y$, Zheng SX, Chen LM, Sun B. Changes of serum oxidative stress indexes of patients with type II diabetes. J Prac Diabet 2005; 2(2):14-17.

14. Liu Y. Curative effect of intravenous pumping of insulin with micro pump in treating diabetic ketoacidosis. Prac Clin Med 2011; 12(6): 19-20.

15. Liu GY, Liao XD, Gu Y, Huang XL, Wang CW. Clinical Observation of Continuous Pumping of Insulin with Micro Pump in the Treatment of Diabetic Ketoacidosis. Chin J Mod Drug Appli 2012; 6(21): 84-85.

16. Li J, Shen XP, Zou SB, Wu HJ. Changes of IL-6 and oxidative stress of elder patients with diabetic ketoacidosis. J Cell Mol Immunol 2009; 25(6): 537-539.

17. Li P. Comparison of two micro pump therapies in treating diabetes in combination with ketoacidosis. J Prac Med Tech 2006; 13(12): 2108-2109.

18. Scaramuzza $A E$, lafusco $D$, Rabbone I, Bonfanti $R$, Lombardo F, Schiaffini R, Buono P, Toni S, Cherubini V, Zuccotti GV, et al. Use of integrated real-time continuous glucose monitoring/insulin pump system in children and adolescents with type 1 diabetes: a 3-year follow-up study. Diabet Tech Ther 2011; 13(2): 99-103.

19. Wang GH, Xu RJ, Zhang ZS, Wang XJ. Clinical Significance of Determination of Serum $C$ - peptide Levels. J Radioimmanol 2006; 19(1):15-16.

20. Zhou H, Xu Y, He W. Changes in Thyroid Function and Related Hormones in the Critically III Patients. J Capital Univ Med Sci 2007; 28(5): 587-591.

21. Scoscia E, Baglioni S, Eslami A, lervasi G, Monti S, Todisco T. Low triiodothyronin (eT3) state a predictor of outcome in respiratory failure? Results of a clinical pilot study. Eur J Endocrinol 2004; 151(5): 557-560.

22. Qiu H, Xie Y, Han M. Study on the change of cytokines and neurohormonal activation in the serum of traumatic patients. Mod Hospital 2012; 5(12): 18-20. 